\title{
Removal of methyl orange from aqueous solution using synthetic clay type MgAl-LDH: Characterization, Isotherm and thermodynamic studies
}

\author{
Ahmed Zaghloul, Abdeljalil Ait Ichou, Ridouan Benhiti, M'hamed Abali, Amina Soudani, Mohamed \\ Chiban, Mohamed Zerbet and Fouad Sinan* \\ Laboratory LACAPE, Faculty of Science, University Ibn Zohr, BP. 8106, Hay Dakhla, Agadir, Morocco.
}

\begin{abstract}
The MgAl-LDH adsorbent (2:1) was developed by the urea method and used as an adsorbent for the removal of methyl orange from aqueous solution. The synthesized adsorbent was characterized by a different analytical technique: scanning electron microscope SEM, X-ray diffraction (XRD) and infrared spectroscopy (FTIR). The effect of adsorption parameters such as solution $\mathrm{pH}$, initial concentration of dye, and the temperature was studied using a static system. X-ray diffraction analysis of the samples confirms the crystal structure of the MgAlLDH material. The MgAl-LDH adsorbent was efficient in removing MO from aqueous solution, and maximum removal of $98.5 \%$ was observed in the $\mathrm{pH}$ range from 2 to 10 . The maximum adsorption capacity of $\mathrm{MgAl}-\mathrm{LDH}$ (2:1) was calculated from the Langmuir isotherm; the maximum quantity is $1250 \mathrm{mg}$. $\mathrm{g}^{-1}$. The determination of the thermodynamic parameters indicates that the reaction between methyl orange and MgAl-LDH (2:1) is spontaneous and exothermic $\left(\Delta \mathrm{H}^{\circ}<0\right.$ and $\left.\Delta \mathrm{G}^{\circ}<0\right)$.It can be concluded that $\mathrm{LDH}$ adsorbent can be used effectively for the removal of anionic dyes from industrial wastewater.
\end{abstract}

Keywords: Layered double hydroxides; Adsorption; Methyl orange; Wastewater treatment.

\section{Introduction}

Because of their accumulation (in both effluents and environment), the use of chemicals leads to severe environmental problems directly or indirectly (chronic toxicity) arising from these compounds or their degradation products. More than $7 \times 10^{5}$ tons and about 10000 different types of dyes and pigments are produced every year around the world ${ }^{1}$. It is estimated that 10 to $15 \%$ of the dye is lost in the effluent ${ }^{2}$.

Methyl orange (MO), which is widely used in dyeing industries, is known to be highly toxic, carcinogenic and mutagenic ${ }^{3,4}$. Therefore, it is imperative to get rid of this dye from a waste stream before it is discharged into aqueous bodies. Various effluent treatment techniques such as adsorption ${ }^{5}$, membrane filtration ${ }^{6}$, chemical oxidation ${ }^{7}$, ozonation ${ }^{8}$, biological treatment ${ }^{9}$, ion exchange ${ }^{10}$, coagulation and flocculation ${ }^{11}$ have been widely used to remove dyes and especially methyl orange from an aqueous medium. From all the processing techniques, adsorption is widely adopted because of its high removal efficiency, low process cost and easy to use. Various materials have been studied for adsorption reduction of dyes in wastewater. These materials include plants, activated carbon ${ }^{12}$, chitosan ${ }^{13}$, fly

*Corresponding author : Fouad Sinan

Email address: f.sinan@uiz.ac.ma

DOI: http://dx.doi.org/10.13171/mjc92190925728fs ash $^{14}$, rice husks ${ }^{15}$, zeolites ${ }^{16}$, ferrite nanoparticles ${ }^{17}$. In the current state, researchers' attention is directed towards the exploration of new adsorbents with high adsorption capacities for different pollutants. Lamellar double hydroxides (LDH), also called hydrotalcite clays or anionic clays, have been attracted attention in recent years because of its application in various fields, including the water treatment sector ${ }^{18}$. LDH has been considered as excellent adsorbents for wastewater treatment because of their large surface area, their layered structure and their interlayer ion exchange. It is efficient, inexpensive, simple, easy to perform and insensitive to toxic substances ${ }^{18}$. Previous works on dye adsorption ${ }^{19,20}$ have proven their usefulness as adsorbents for some pollutants. Among the different types of LDH species, a compound consisting of a dual compound of $\mathrm{MgAl}-\mathrm{LDH}$ hydroxides with carbonate as interlayer anions is commonly used for various applications 21, 22. In this study, we synthesized a clay using the urea method; then, we characterized our adsorbent using various techniques, such as X-ray diffraction (XRD), Scanning Electron Microscopy (SEM), X-ray emission spectroscopy (EDX) and infrared spectroscopy (FT-IR), Batch adsorption experiments were performed to study the

Received August 20, 2019

Accepted August 27, 2019

Published September 25, 2019 
effect of $\mathrm{pH}$, initial $\mathrm{MO}$ concentration and temperature on the removal of MO from water. The adsorption equilibrium and thermodynamic parameters of $\mathrm{MO}$ on $\mathrm{MgAl}-\mathrm{LDH}$ (2:1) were also discussed.

\section{Materials and methods}

Table1. Characteristics of Methyl orange.

\subsection{Preparation of adsorbate}

The Methyl orange used in this study was purchased from Panreac (Barcelona, Spain). A Stock solution of 1g. $\mathrm{L}^{-1}$ of methyl orange dye was prepared with double distilled water. The working solutions were obtained by diluting the stock solution. The molecular structure and some physicochemical characteristics of used dye are shown in Table 1.

\begin{tabular}{|l|} 
Molecular structure \\
\hline $\begin{array}{l}\text { Chemical formula } \\
\lambda \text { max (nm) } \\
\text { Type of dye } \\
\left.\text { Molar mass (g. mol }{ }^{-1}\right)\end{array}$ \\
\hline
\end{tabular}

\subsection{Preparation of MgAl-LDH}

Urea is a fragile Brønsted base $\left(\mathrm{pK}_{\mathrm{b}}=13.8\right)$, highly soluble in water, and its hydrolyzing rate may be controlled by the temperature, its decomposition giving rise to ammonium carbonate:

$$
\mathrm{NH}_{2}-(\mathrm{C}=\mathrm{O})-\mathrm{NH}_{2}+2 \mathrm{H}_{2} \mathrm{O} \rightarrow 2 \mathrm{NH}_{4}^{+}+\mathrm{CO}_{3}^{2-}
$$

According to Shaw and Bordeaux ${ }^{23}$ hydrolysis of urea proceeds in two steps, the formation of ammonium cyanate $\left(\mathrm{NH}_{4} \mathrm{CNO}\right)$ as the ratedetermining step, and the fast hydrolysis of the cyanate to ammonium carbonate.

The same conditions were described by Costantino et al. ${ }^{24}$ were used to prepare $\mathrm{MgAl}-\mathrm{LDH}: \mathrm{NH}_{2} \mathrm{CONH}_{2}$ (AppliChem > 99\%) is dissolved in an aqueous solution of $\mathrm{AlCl}_{3} 6 \mathrm{H}_{2} \mathrm{O}$ (AppliChem > 95\%) and $\mathrm{MgCl}_{2} \cdot 6 \mathrm{H}_{2} \mathrm{O}$ (LobaChemie > 98\%). Solid urea was added to $0.5 \mathrm{~mol} . \mathrm{dm}^{-3}$ metal solutions, having a molar ratio $\left(\mathrm{Mg}^{2+} / \mathrm{Al}^{3+}\right)$ equal to 2 , to reach urea/metal ions molar ratio of 3.3. The clear solution was refluxed and at $100^{\circ} \mathrm{C}$ to start the hydrolysis reaction. The $\mathrm{pH}$ was measured all along with the reaction with an industrial $\mathrm{pH}$ electrode for high temperature. The reaction was stopped after 36 hours, and the solids were separated from the solution and washed with distilled water.

\subsection{Characterization of MgAl-LDH (2:1)}

The crystalline structure of the obtained product was characterized by X-ray diffraction (D221-18-X-6 XRD-ray instrument, $2 \theta=11.50^{\circ}$ to $65.94^{\circ}$ ) with $\mathrm{CuK}_{\alpha}$ radiation $(1.54 \AA)$. The morphology observations were carried out on field emission scanning electron microscope (SEM, UATRS CNRST). FT-IR study was carried out using FTIR
8400S Shimadzu-FTIR spectra were recorded, in the range of $400-4000 \mathrm{~cm}^{-1}$ with $\mathrm{KBr}$ pellets technique.

\subsection{Adsorption study of methyl orange}

Adsorption experiments were evaluated in batch equilibrium mode. All experiments were conducted by mixing $40 \mathrm{~mL}$ of aqueous dye solutions with $20 \mathrm{mg}$ of the adsorbent. The appropriate $\mathrm{pH}(2-12)$ of the mixture was adjusted using solutions of $\mathrm{HCl}(0.1 \mathrm{~N})$ and $\mathrm{NaOH}(0.1 \mathrm{~N})$. The adsorption isotherms were determined at $293.15 \mathrm{~K}$ with initial concentrations of MO (50-800 mg. $\left.\mathrm{L}^{-1}\right)$. The temperature effect was achieved at $\left(\mathrm{T}=25,30,35^{\circ} \mathrm{C}\right)$ After stirring, the mixture was centrifuged at $3000 \mathrm{rpm}$ for 15 minutes to separate the spent adsorbent from the residual dye. The equilibrium concentration of dye solution was measured using UV-vis spectrometer (UV-2005) at the max value of $464 \mathrm{~nm}$ for MO. The amount of dye adsorbed at equilibrium $\mathrm{q}_{\mathrm{e}}\left(\mathrm{mg} . \mathrm{g}^{-1}\right)$ is given by the following equation:

$\mathrm{q}_{\mathrm{e}}=\frac{\left(\mathrm{C}_{0}-\mathrm{C}_{\mathrm{e}}\right)}{\mathrm{m}} \times \mathrm{V}$

With $\mathrm{q}_{\mathrm{e}}$ is the equilibrium adsorption capacity $\left(\mathrm{mg} . \mathrm{g}^{-1}\right), \mathrm{C}_{0}$ and $\mathrm{Ce}$ are the initial and equilibrium concentration (mg. $\mathrm{L}^{-1}$ ) of $\mathrm{MO}$ in solution, $\mathrm{m}$ is the adsorbent mass (mg), $\mathrm{V}$ is the Volume of the solution (ml).

\section{Results and Discussion}

\subsection{Characterization of Mg Al-LDH}

Figure 1 shows the XRD diffractogram of MgAlLDH. It indicates a high degree of crystallinity; these peaks were located at approximately $11.50^{\circ} ; 23.12^{\circ}$; 34. $89^{\circ} ; 39.36^{\circ}$. $46.58^{\circ} ; 52.80^{\circ} ; 56.06^{\circ} ; 60.75^{\circ}$; $62.03^{\circ} .65 .94^{\circ}$ and can be assigned to plans (003); 
(006); (012); (015); (018); (1010); (0111); (110); (113); (116). Various researchers have reported similar results ${ }^{17,25}$. All diffraction peaks are indexed under a hexagonal structure and crystallized in a Rhombohedral crystal system with a spatial group
$\mathrm{R}-3 \mathrm{~m}$, the number of pattern $\mathrm{Z}=1$ and a density $\mathrm{d}=2.09$. The interlayer $\mathrm{d}$-spacing $\mathrm{d}_{003}$ and $\mathrm{d}_{006}$ of $\mathrm{Mg}-\mathrm{Al} \mathrm{LDH}$ were found to be $7.69 \AA$ and $3.84 \AA$. The $\mathrm{d}_{003}$ was twice as much as $\mathrm{d}_{006}$, suggesting a favorable layer structure ${ }^{26}$.

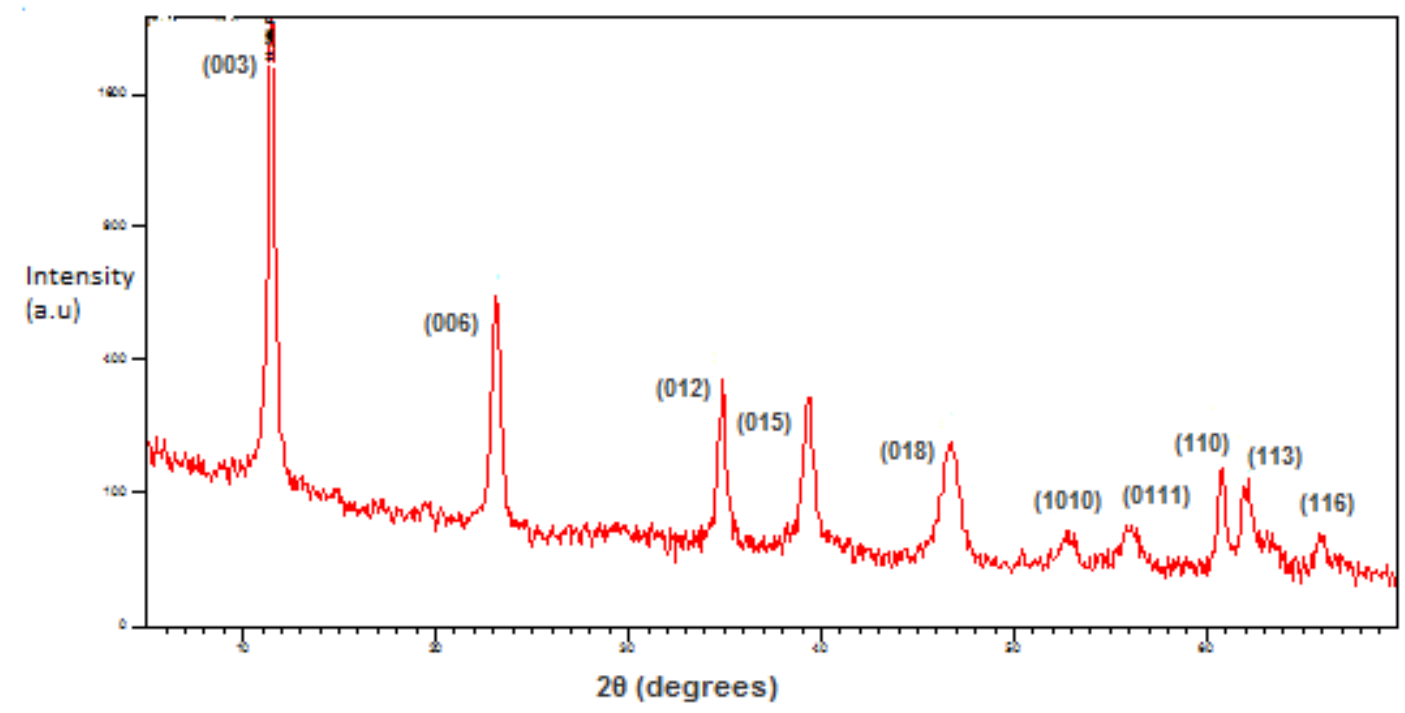

Figure 1. X-ray diffraction of MgAl-LDH
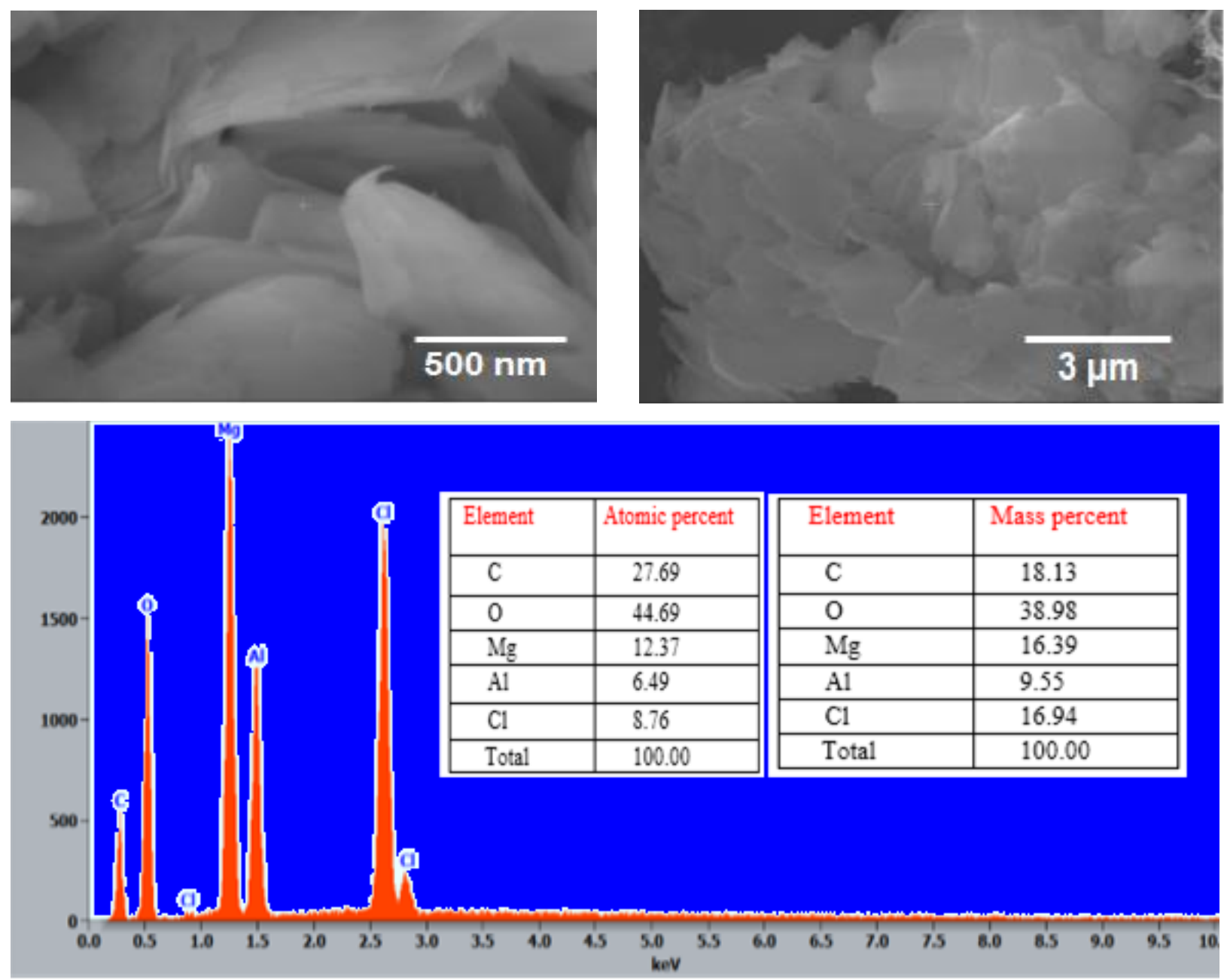

Figure 2. SEM-EDS analysis of MgAl-LDH 
Figure 2 presents the SEM-EDX; the two images present a morphology in the form of porous sheets. The surface of MgAl-LDH forms a compact hexagonal stack; similar studies are reported by ${ }^{25,1}$. The spectre (EDX) indicates the presence of magnesium, aluminium, chloride, the molar ratio of $\mathrm{Mg} / \mathrm{Al}$ was 1.90 which is in a good agreement with the molar ratio $\left(\mathrm{Mg}^{2+} / \mathrm{Al}^{3+}=2\right)$ used during the preparation of $\mathrm{Mg}$ Al-HDL (2:1).
Figure 3 displays the infrared spectra of the samples measured between 4000 and $400 \mathrm{~cm}^{-1}$. The peak at $3453 \mathrm{~cm}^{-1}$, related to the $\mathrm{O}-\mathrm{H}$ stretching vibration $\mathrm{v}(\mathrm{O}-\mathrm{H})$ of the metal hydroxide layer and interlayer water molecules ${ }^{27}$. The band at $2368 \mathrm{~cm}^{-1}$ is typically assigned to $\mathrm{CO}_{2}$ from air ${ }^{28}$. The peak at $1615 \mathrm{~cm}^{-1}$ to the $\mathrm{OH}$ stretching band of $\mathrm{H}_{2} \mathrm{O}^{29}$. The band observed at $1358 \mathrm{~cm}^{-1}$ is attributed to the stretching vibration of $\mathrm{CO}_{3}{ }^{2-}{ }^{30}$. The bands in the range of $542-779 \mathrm{~cm}^{-1}$ are attributed to M-oxygen-M stretching $(\mathrm{M}=\mathrm{Mg} \text { and } \mathrm{Al})^{31}$.

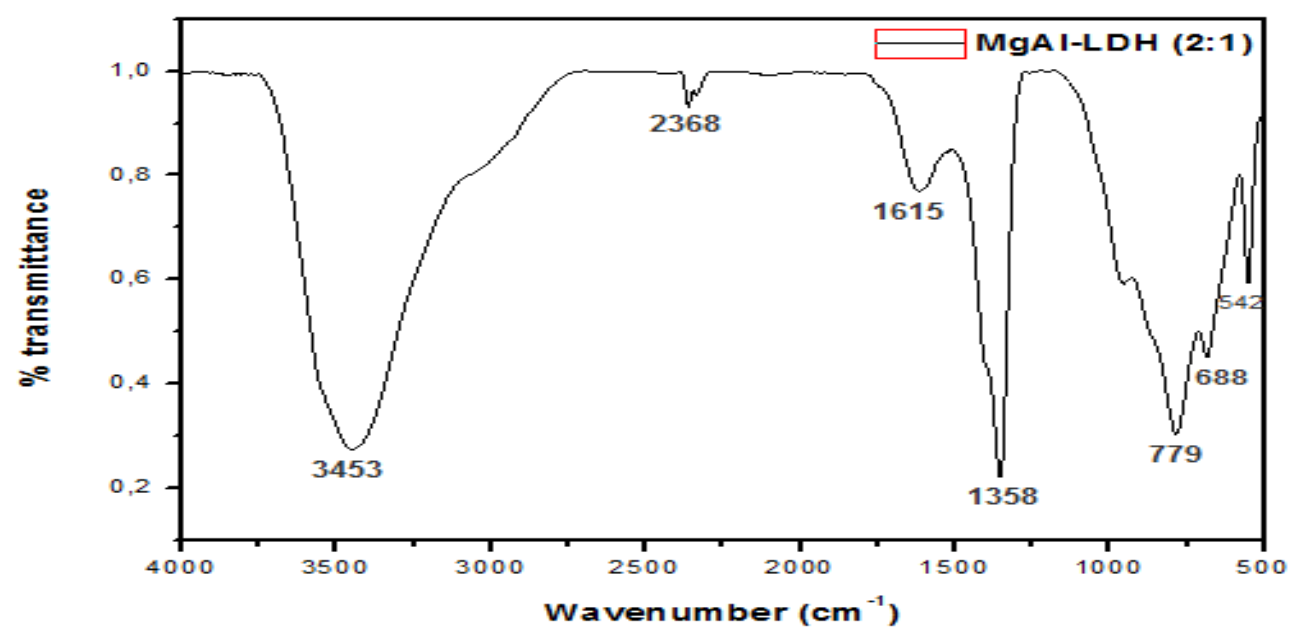

Figure 3. FTIR spectra of $\mathrm{Mg}-\mathrm{Al}-\mathrm{LDH}$

\subsection{Adsorption of methyl orange}

\subsubsection{Effect of initial $\mathrm{pH}$ on dye adsorption}

The $\mathrm{pH}$ of the solution is one of the most important parameters in the adsorption process. Figure 4 shows the effect of the initial $\mathrm{pH}$ on the adsorption of $\mathrm{MO}$ over $\mathrm{pH}$ range (2 to 12$)$. In the range of $\mathrm{pH}$ from 2 to $\mathrm{pH}=10$, adsorption remains constant with an adsorption amount of $197 \mathrm{mg}$. $\mathrm{g}^{-1}$, due to the strong

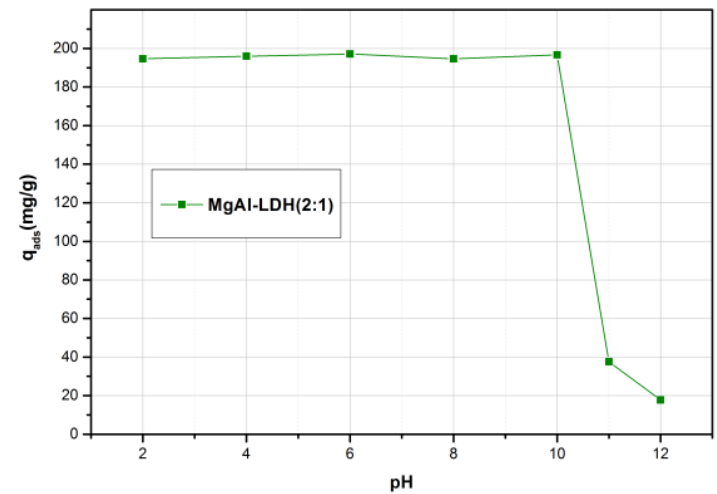

Figure 4. Effect of $\mathrm{pH}$ on adsorption of methyl orange $\left(\mathrm{Ci}=100 \mathrm{mg} / \mathrm{L}, \mathrm{m}=20 \mathrm{mg}, \mathrm{V}=40 \mathrm{ml}, \mathrm{t}=3 \mathrm{~h}, \mathrm{~T}=25^{\circ} \mathrm{C}\right)$

\subsubsection{Effect of initial MO concentrations}

The effect of initial MO concentration on its removal by MgAl-LDH was studied at different concentrations ranging from $50 \mathrm{mg}$. $\mathrm{L}^{-1}$ to $800 \mathrm{mg}^{-1}$ (Figure 5). electrostatic interactions between the solute (MO) and the positively charged $\mathrm{H}^{+}$surface of the adsorbent. For a $\mathrm{pH}$ value of 10 , there is a decrease for adsorption explained by the competition between excess $\mathrm{OH}^{-}$in a basic solution for adsorption sites with MO anions. A similar study of the elimination of MO by another adsorbent has been reported by other researchers ${ }^{1,32}$.

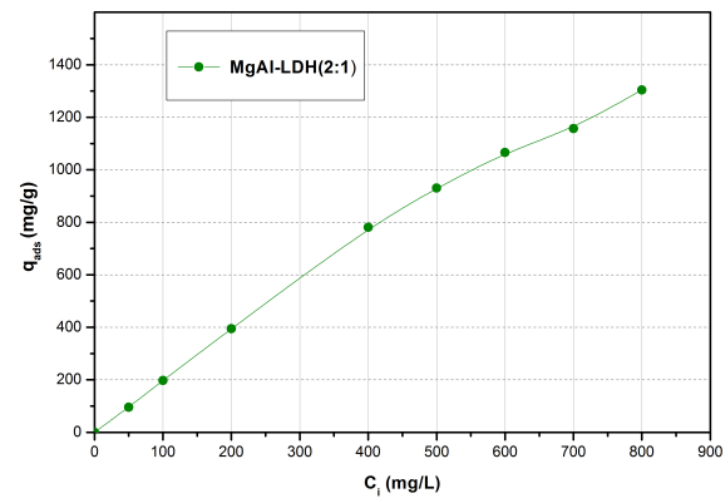

Figure 5. Effect of initial concentration of Methyl orange $\left(\mathrm{m}=20 \mathrm{mg}, \mathrm{V}=40 \mathrm{ml}, \mathrm{t}=3 \mathrm{~h}, \mathrm{~T}=25^{\circ} \mathrm{C}\right)$

Analysis of this curve shows that the adsorbed amount of MgAl-LDH (2:1) increases with increasing initial concentration without reaching saturation. 


\subsubsection{Adsorption isotherm}

To understand the mechanisms involved in the adsorption of MO on our material, we have sought to model the isotherms of adsorption (Figure 6) by applying the two most commonly used models: Langmuir and Freundlich. The Langmuir model (Figure 7A) is based on the assumption that the surface is uniform with no interactions between adsorbed molecules; and that, it has defined adsorption sites ${ }^{33}$. This model considers that adsorption takes place through the formation of an adsorbate monolayer and leads to the following equation:

$$
\mathrm{q}_{\mathrm{e}}=\mathrm{q}_{\mathrm{m}} \times \frac{\mathrm{K}_{\mathrm{L}} \times \mathrm{C}_{\mathrm{e}}}{1+\mathrm{K}_{\mathrm{L}} \times \mathrm{C}_{\mathrm{e}}}
$$

With $\mathrm{q}_{\mathrm{m}}$ : Capacity maximum adsorbed $\left(\mathrm{mg} \cdot \mathrm{g}^{-1}\right), \mathrm{K}_{\mathrm{L}}$ : adsorbent characteristic equilibrium constant (L. $\mathrm{mg}^{-1}$ ), dependent on temperature and experimental conditions, $\mathrm{C}_{\mathrm{e}}$ : adsorbate concentration at equilibrium (mg.L $\left.\mathrm{L}^{-1}\right)$.

The linearization of equation (2) leads to:

$$
\frac{1}{q_{e}}=\frac{1}{q_{m} K_{L}} \frac{1}{C_{e}}+\frac{1}{q_{m}}
$$

By plotting $\frac{1}{q_{e}}$ as a function of $\frac{1}{C_{e}}$ this gives a line of slope $\frac{1}{q_{m} K_{L}}$ and ordinate at the origin $\frac{1}{q_{m}}$.The Freundlich isotherm is an empirical equation that assumes that the adsorption surface becomes heterogeneous during the adsorption process. The Freundlich isotherm (Figure 7 B) is expressed by the following equation ${ }^{34}$ :
$\mathrm{q}_{\mathrm{e}}=\mathrm{K}_{\mathrm{F}} \mathrm{C}_{\mathrm{e}}^{1 / \mathrm{n}}$

Where $\mathrm{k}_{\mathrm{F}}$ is a constant related to the binding energy, it can be defined as the adsorption or distribution coefficient and represents the amount of dye adsorbed on the adsorbent for the concentration unit at equilibrium. $\frac{1}{n}$ Indicates the dye adsorption intensity on the adsorbent or surface heterogeneity, which becomes more heterogeneous as the $\frac{1}{n}$ value approaches zero. A value of $\frac{1}{n}$ is below 1 indicates a normal Langmuir isotherm, while $\frac{1}{n}$ above 1 indicates a cooperative adsorption ${ }^{35}$. This equation can also be expressed as:

$\operatorname{Lnq}_{\mathrm{e}}=\frac{1}{n} \mathrm{LnC}_{\mathrm{e}}+\operatorname{Ln} \mathrm{K}_{\mathrm{F}}$

The values of the constants of the adsorption isotherms with correlation coefficients are summarized in Table 2. The value obtained from $\mathrm{R}^{2}$ of MgAl-LDH (2:1) for the Langmuir isotherm was 0.99 at $298 \mathrm{~K}$, which is higher than that of the Freundlich isotherms. This indicated that the Langmuir isotherm fully describes the nature and sorption mechanism of MO on the composite studied. The maximum adsorption capacity of $\mathrm{MgAl}-\mathrm{LDH}$ (2:1) calculated from the Langmuir isotherm was $1250 \mathrm{mg}$. $\mathrm{g}^{-1}$. The result obtained from $\frac{1}{n}$ at $298 \mathrm{~K}$ was 0.34 , indicating that the adsorption system o MOMgAl- LDH $(2: 1)$ was favourable (i.e. $(1<\mathrm{n}<10)$.

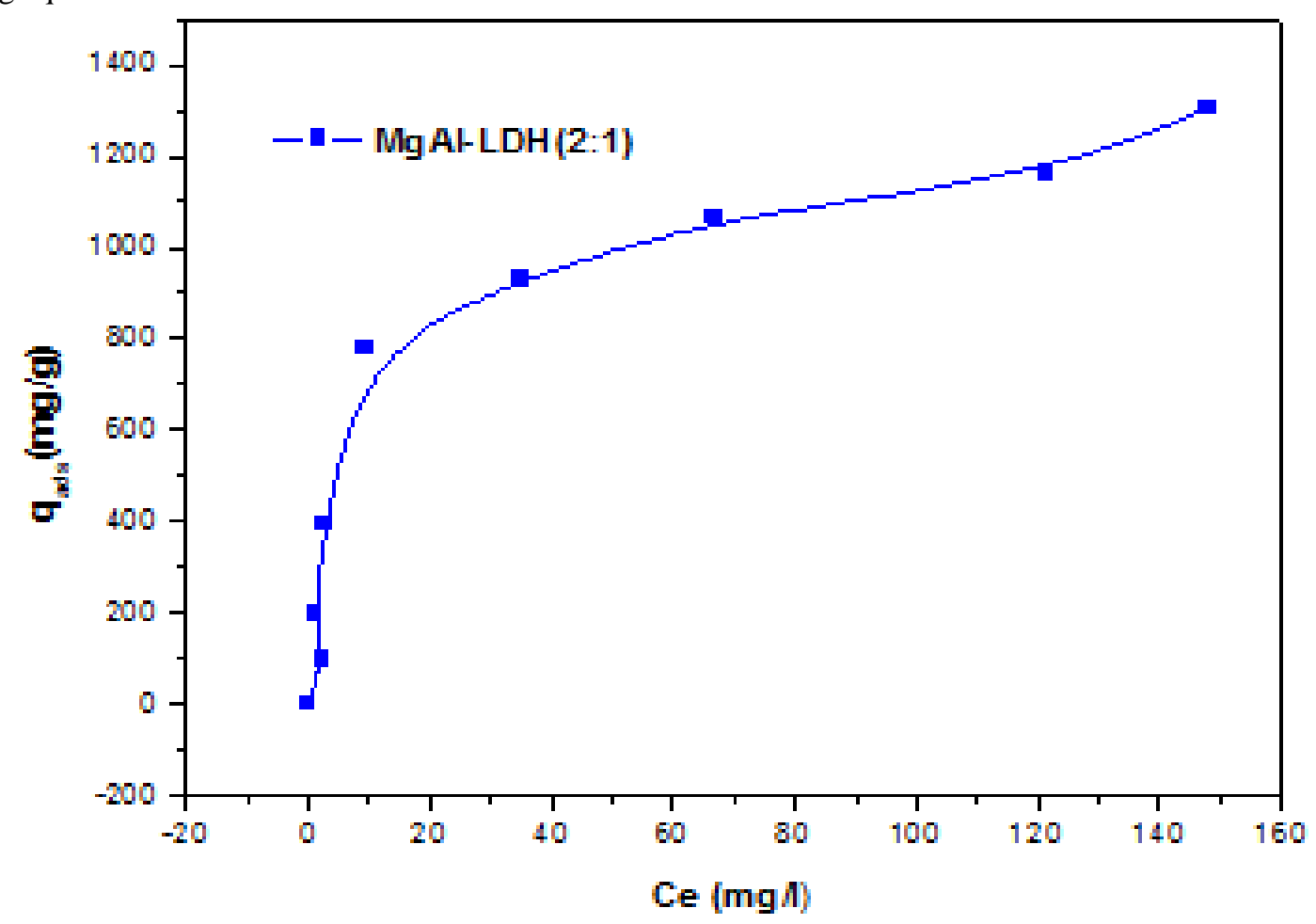

Fig 6. Isotherm of the adsorption of MO by MgAl- LDH (2:1) $\left(\mathrm{m}=20 \mathrm{mg}, \mathrm{V}=40 \mathrm{ml}, \mathrm{t}=3 \mathrm{~h}, \mathrm{~T}=25^{\circ} \mathrm{C}\right)$. 

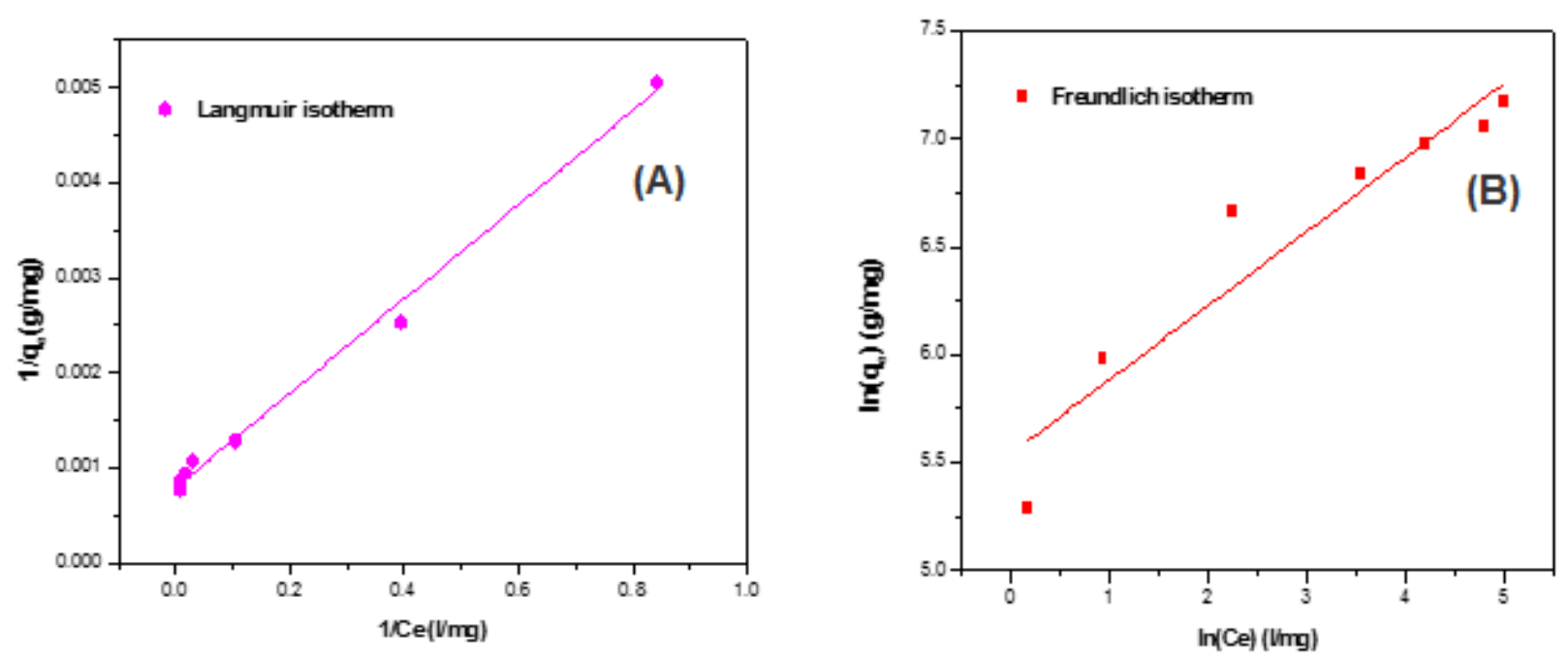

Figure 7. Linear plots of isotherm models of MgAl-LDH (2:1), Langmuir (A), Freundlich (B)

Table 2. Constants of Langmuir and Freundlich isotherm models for MO adsorbed by the MgAl- LDH

3.2.4. Effect of temperature and thermodynamic study in Figure 7, the adsorbed quantity of MO in both concentrations decreased slightly as temperature

\section{Langmuir}

\begin{tabular}{|c|c|c|c|c|c|}
\hline $\mathrm{q}_{\mathrm{m}}\left(\mathrm{mg} \cdot \mathrm{g}^{-1}\right)$ & $\mathrm{K}_{\mathrm{L}}\left(\mathrm{L} \cdot \mathrm{mg}^{-1}\right)$ & $\mathrm{R}^{2}$ & $\mathrm{~K}_{\mathrm{F}}\left(\mathrm{mg} \cdot \mathrm{g}^{-1}\right)$ & $1 / \mathrm{n}$ & $\mathrm{R}^{2}$ \\
\hline 1250 & 0.16 & 0.99 & 254.47 & 0.34 & 0.90 \\
\hline
\end{tabular}

Adsorption is a phenomenon that can be endothermic or exothermic depending on the adsorbent material and the nature of the adsorbed molecules ${ }^{36}$. As shown

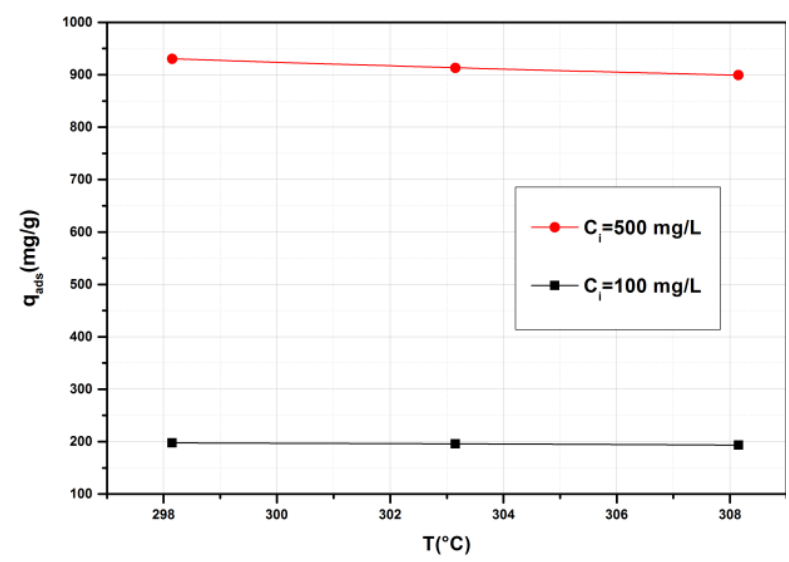

Figure 7. Effect of temperature on $\mathrm{MO}$ by $\mathrm{MgAl}-$ LDH $(2: 1),(m=20 \mathrm{mg}, \mathrm{V}=40 \mathrm{ml}, \mathrm{t}=3 \mathrm{~h})$

Thermodynamic parameters such as standard Gibbs free energy $\left(\Delta \mathrm{G}^{\circ}\right)\left(\mathrm{kJ} \cdot \mathrm{mol}^{-1}\right)$, standard entropy $\left(\Delta \mathrm{S}^{\circ}\right)$ $\left(\mathrm{J} \cdot \mathrm{mol}^{-1} \cdot \mathrm{K}^{-1}\right)$ and standard enthalpy $\left(\Delta \mathrm{H}^{\circ}\right)\left(\mathrm{Kj}^{\mathrm{m}} \mathrm{mol}^{-1}\right)$ were determined using the following equations ${ }^{1}$ :

$\mathrm{K}_{\mathrm{d}}=\frac{\mathrm{q}_{\mathrm{e}}}{\mathrm{C}_{\mathrm{e}}}$

$\Delta \mathrm{G}^{\circ}=-\mathrm{RT} \operatorname{Ln} \mathrm{K}_{\mathrm{d}}$ increases. Adsorption of $\mathrm{MO}$ onto $\mathrm{MgAl}-\mathrm{LDH}(2: 1)$ is an exothermic process; the adsorption capacity decreased with an increase in solution temperature.

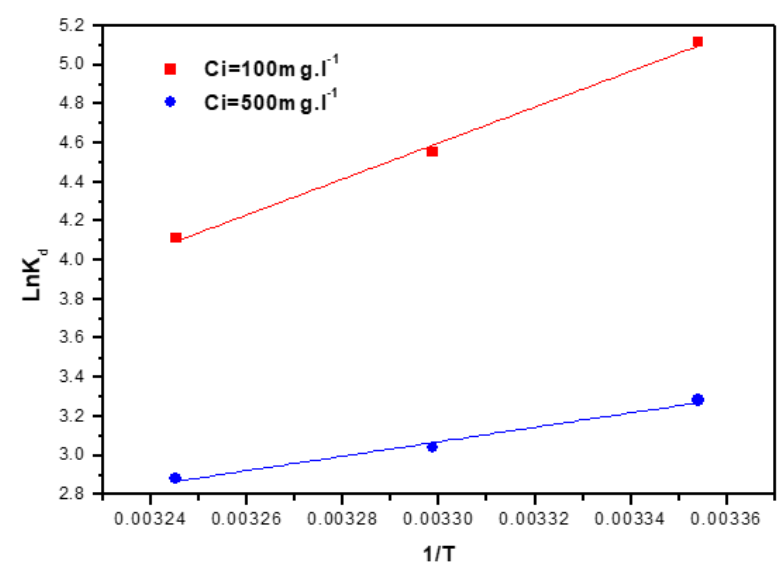

Figure 8. Linear plots of $\ln \mathrm{K}_{\mathrm{d}}$ vs $\frac{1}{T}$

$\operatorname{Ln} K_{d}=\frac{\Delta S^{\circ}}{R}-\frac{\Delta H^{\circ}}{R T}$

Where $K_{d}\left({\left.\mathrm{~L} . \mathrm{g}^{-1}\right)}\right.$ is the thermodynamic equilibrium constant, $\mathrm{T}(\mathrm{K})$ is the temperature and $\mathrm{R}(8.314 \mathrm{~J} . \mathrm{mol}$ ${ }^{-1} \mathrm{~K}^{-1}$ ) is the universal gas constant, carrying $\ln \mathrm{K}_{\mathrm{d}}$ according to $\frac{1}{T}$ for both concentrations. 
The linear curves of $\mathrm{LnK}_{\mathrm{d}}$ concerning $\frac{1}{T}$ for the adsorption of $\mathrm{MO}$ on the $\mathrm{MgAl}-\mathrm{LDH}$ composite (2:1) are shown in Figure 8, and the thermodynamic parameters are shown in Table 3. The negative values of $\Delta \mathrm{G}^{\circ}$ in Table 3 at all temperatures show that the adsorption of MO. on MgAl-LDH (2:1) was thermodynamically possible and spontaneous ${ }^{37}$, for both concentrations, and the negative values of $\Delta \mathrm{H}^{\circ}$ indicated that the adsorption process was exothermic. Besides, the negative values of $\Delta \mathrm{S}^{\circ}$ indicated a more critical order of reaction during the adsorption, which can be attributed to the adhesion of the adsorbate with the adsorbent resulting in a decrease in the degree of freedom of the system ${ }^{38}$.

Table 3. Thermodynamic parameters for MO adsorption on MgAl-LDH adsorbent (2:1).

\begin{tabular}{|c|c|c|c|c|c|}
\hline$C_{i}\left(m g . L^{-1}\right)$ & $\mathbf{T}(\mathbf{K})$ & $\mathbf{K}_{\mathbf{D}}$ & $\Delta \mathbf{G}^{\circ}\left(\mathrm{KJ}^{\mathrm{J}} \mathrm{mol}^{-1}\right)$ & $\Delta S^{\circ} \underset{1}{\left(\mathrm{~J}^{\prime} \mathrm{mol}^{-1} \cdot \mathrm{K}^{-}\right.}$ & $\Delta \mathrm{H}^{\circ}\left(\mathrm{KJ} \mathrm{mol}^{-1}\right)$ \\
\hline \multirow[t]{3}{*}{100} & 298.15 & 166.22 & -12.67 & \multirow[t]{3}{*}{-214.23} & \multirow[t]{3}{*}{-76.50} \\
\hline & 303.15 & 95.05 & -11.28 & & \\
\hline & 308.15 & 61.08 & -10.19 & & \\
\hline \multirow[t]{3}{*}{500} & 298.15 & 26.67 & -8.13 & \multirow[t]{3}{*}{-75.92} & \multirow[t]{3}{*}{-30.74} \\
\hline & 303.15 & 20.93 & -7.66 & & \\
\hline & 308.15 & 17.84 & -7.38 & & \\
\hline
\end{tabular}

\subsubsection{Comparison with other adsorbents}

The adsorption capacities of various adsorbents towards the adsorption of methyl orange, as reported in the literature presented in Table 4. Based on a comparison window between this work and other data reported in the literature, we found that our adsorbent (MgAl-LDH (2:1)) is a better adsorbent for MO removal.

Table 4. Adsorption capacity $\left(\mathrm{q}_{\max }, \mathrm{mg}\right.$. $\left.\mathrm{g}^{-1}\right)$ of MO reported in the literature.

\begin{tabular}{|l|c|c|c|}
\hline adsorbent & Cinitial $\left(\mathbf{m g . L ^ { - 1 }}\right)$ & qmax $\left(\mathbf{m g . g}^{-\mathbf{1}}\right)$ & Reference \\
\hline NiFe-LDH (2:1) & $20-200$ & 358.42 & 1 \\
\hline NiFe- LDH (1:1) & $20-200$ & 387.59 & 1 \\
\hline ZnMgAl-CO3 LDH & $10-100$ & 683.9 & 39 \\
\hline NiFe- LDH & - & 205.76 & 40 \\
\hline Lapindo volcanic mud & $30-300$ & 333.3 & 41 \\
\hline Zn/Al-LDO & $50-200$ & 181.9 & 42 \\
\hline MgNiAl & $10-500$ & 375.4 & 35 \\
\hline Activated alumina & - & 9.8 & 43 \\
\hline Cork powder & - & 16.66 & 44 \\
\hline MgAl- LDH (2:1) & $50-800$ & 1250 & This study \\
\hline
\end{tabular}

\section{Conclusion}

In this study, a new material MgAl-LDH $(2: 1)$ was developed using the urea method; Different physicochemical techniques were used for LDH characterization such as Scanning Electron Microscopy (SEM), X-ray diffraction and infrared spectroscopy (FT-IR). The adsorbent was used to evaluate their adsorption capacity towards methyl orange. The optimum $\mathrm{pH}$ for the removal of $\mathrm{MO}$ was obtained in the $\mathrm{pH}$ range from 2 to 10 , the obtained results indicate that the adsorption of MO on the MgAl-LDH adsorbent (2:1) was better described by the Langmuir model with a good correlation $\left(\mathrm{R}^{2}=0.99\right)$ and a maximum adsorption amount $\left(\mathrm{q}_{\max }\right.$ $=1250 \mathrm{mg} \cdot \mathrm{g}^{-1}$ ) on one hand. On the other hand, the thermodynamic data showed that the adsorption of the MO on the surface of MgAl-LDH $(2: 1)$ is of exothermic and spontaneous nature $\left(\Delta \mathrm{H}^{\circ}<0\right.$ and
$\left.\Delta \mathrm{G}^{\circ}<0\right)$. These exciting results offer several perspectives, such as the recycling of the material used. The synthesized carrier will also be tested for trapping other organic solvents.

\section{References}

1- M. Zubair, N. Jarrah, Ihsanullah, A. Khalid, M. Manzar, T. Kazeem, M. A. Al-Harthi, StarchNiFe-layered double hydroxide composites: Efficient removal of methyl orange from the aqueous phase, Journal of Molecular Liquids, 2018, 249, 254-264.

2- V.K. Gupta, R. Jain, T.A. Saleh., A Nayak, S. Malathi, S. Agarwal, Equilibrium and thermodynamic studies on the removal and recovery of Safranine-T Dye from industrial effluents, Sep. Sci. Technol, 2011, 46, 839-846. 
3- F. Ling, L. Fang, Y. Lu, J. Gao, F. Wu, M. Zhou, B. $\mathrm{Hu}, \mathrm{A}$ novel $\mathrm{CoFe}$ layered double hydroxides adsorbent: high adsorption amount for methyl orange dye and fast removal of $\mathrm{Cr}$ (VI), Microporous Mesoporous Mater, 2016. 234, 230-238.

4- B.H.A.I. Tan, T.T.O.W. Teng, A.K.M.O. M, Removal of dyes and industrial dye wastes by magnesium chloride, Water Res, 2000, 34, 597-601.

5- A. Abbas, B.A. Abussaud, N.A.H. Al-Baghli, Ihsanullah. M, Khraisheh. M.A Atieh, Benzene removal by iron oxide nanoparticles decorated carbon nanotubes, J. Nanomater, 2016.

6- M. Liu, Q. Chen, K. Lu, W. Huang, Z. Lü, C. Zhou, S. Yu, C. Gao, High efficient removal of dyes from aqueous solution through nanofiltration using diethanolamine-modified polyamide thin-film composite membrane, Sep. Purif. Technol, 2017, 173, 135-143.

7- A. Uygur, Reuse of decolourised wastewater of azo dyes containing dichlorotriazinyl reactive groups using an advanced oxidation method, Color. Technol, 2001, 117, 111-113.

8- K. Turhan, Z. Turgut, Decolorization of direct dye in textile wastewater by ozonization in a semi-batch bubble column reactor, Desalination, 2009,242, 256-263.

9- A. Stolz, Basic and applied aspects in the microbial degradation of azo dyes, Appl. Microbiol. Biotechnol, 2001, 56, 69-80.

10- C.H. Liu, J.S. Wu, H.C. Chiu, S.Y. Suen, K.H. Chu, Removal of anionic reactive dyes from water using anion exchange membranes as adsorbers, Water Res, 2007, 41, 1491-1500.

11- F. Harrelkas, A. Azizi, A. Yaacoubi, A. Benhammou, M.N. Pons, Treatment of textile dye effluents using coagulation-flocculation coupled with membrane processes or adsorption on powdered activated carbon, Desalination, 2009, $235,330-339$.

12- F. Rozada, L.F. Calv, A.I. García, J. MartínVillacorta, M. Otero, dye adsorption by sewage sludge-based activated carbons in batch and fixed-bed systems, Bioresour. Technol, 2003, 87, 221-230.

13- M.S. Chiou, P.Y. Ho, H.Y. Li, Adsorption of anionic dyes in acid solutions using chemically cross-linked chitosan beads, Dyes Pigments, 2004, 60, 69-84.

14- P. Janos, H. Buchtova, M. Rznarova, Sorption of dyes from aqueous solutions onto fly ash, Water Res, 2003, 37, 4938-4944.

15-Y. Gou, S. Yang, W. Fu, J. Qi, R. Li, Z. Wang, $\mathrm{H}$. Xu, Adsorption of malachite green on microand mesoporous rice husk-based active carbon, Dyes Pigments, 2003 56, 219-229.

16- O. Ozdemir, B. Armagan, M. Turan, M.S. Çelik, Comparison of the adsorption characteristics of azo-reactive dyes on mesoporous minerals, Dyes Pigments, 2004, 62, 49-60.
17- X. Wu, W. Wang, F. Li, S. Khaimanov, N. Tsidaeva, PEG-assisted hydrothermal synthesis of $\mathrm{CoFe}_{2} \mathrm{O}_{4}$ nanoparticles with enhanced selective adsorption properties for different dyes, Appl. Surf. Sci, 2016, 389, 1003-1011.

18- F.L. Theiss, S.J. Couperthwaite, G.A. Ayoko, R.L. Frost, A review of the removal of anions and oxyanions of the halogen elements from aqueous solution by layered double hydroxides, J. Colloid Interface Sci, 2014, 417, 356-368.

19- M. Zhu, Y. Li, M. Xie., H. Xin, Sorption of an anionic dye by uncalcined and calcined layered double hydroxides: a case study, J. Hazard. Mater, 2005, 120, 163-171.

20- R. Bastiani, I.V. Zonno, I.A.V. Santos, C.A. Henriques, J.F.L. Monteiro, Influence of thermal treatments on the basic and catalytic properties of $\mathrm{MgAl}$-mixed oxides derived from hydrotalcite, Braz. J. Chem. Eng, 2004, 21,193-202.

21- O. Aschenbrenner, P. Guire, S. Alsamaq, J. Wang, S. Supasitmongkol, B. Al-Duri, P. Styring, J. Wood, Adsorption of carbon dioxide on hydrotalcite-like compounds of different compositions, Chem. Eng. Res. Des, 2011, 89, 1711-1721.

22-W.T. Reichle, Synthesis of anionic clay minerals (mixed metal hydroxides hydrotalcite), Solid State Ionics, 1986, 22, 135-141.

23- W.H.R. Shaw and J.J. Bordeaux, the Decomposition of Urea in Aqueous Media, J. Am. Chem. Soc., 1955, 77, 4729

24- U. Costantino, F. Marmottini, M. Nocchetti, R. Vivani New Synthetic Routes to HydrotalciteLike Compounds, European journal of inorganic chemistry 1998 1439-1446.

25- R. Elmoubarki, F. Mahjoubi, A. Tonsadi, M. Abdennouri, M. Sadiq, S. Qourzal, A. Zouhri, N. Barka. Ni/Fe and $\mathrm{Mg} / \mathrm{Fe}$ layered double hydroxides and their calcined derivatives: preparation, characterization and application on textile dyes removal, Journal of Materials Research and Technology, 2017, 3, 271-283.

26- D.G. Evans, R.C.T. Slade, Structural aspects of layered double hydroxides, J. Struct. Bond, 2006, $119,1-87$

27- S. Aisawa, H. Hirahara, H. Uchiyama, S. Takahashi, and E. Narita, Synthesis and thermal decomposition of Mn-Al layered double hydroxides, J. Solid State Chem., 2002, 167, 152-159

28- M. Yoshida, P. Koilraj, X. Qiu1, T. Hirajima, K. Sasaki, Sorption of arsenate on $\mathrm{MgAl}$ and $\mathrm{MgFe}$ layered double hydroxides derived from calcined dolomite, Journal of Environmental Chemical Engineering, 2015, 2213-3437.

29- H.T. Kang, K. Lv, S.L. Yuan, Synthesis, characterization, and SO2 removal capacity of $\mathrm{MnMgAlFe}$ mixed oxides derived from hydrotalcite-like compounds, Appl. Clay Sci., 2013, 72, 184-190. 
30- O.P. Ferreira, O.L. Alves, D.X. Gouveia, A.G. Souza Filho, J.A.C. de Paiva, J. Mendes Filho, Thermal decomposition and structural reconstruction effect on $\mathrm{Mg}-\mathrm{Fe}$ based hydrotalcite compounds, J. Solid State Chem., 2004, 177, 3058-3069.

31- J.T. Kloprogge, R.L. Frost, Infrared and Raman spectroscopic studies of layered double hydroxides (LDHs), in V. Rives (Ed.), Layered Double Hydroxides: Present and Future, Nova Sci. Pub. Inc., New York, 2001, pp. 139-192.

32- R. Huang, Adsorption of methyl orange onto protonated cross-linked chitosan, Arab. J. Chem, 2017, 10, 24-32.

33- I. Langmuir, The constitution and fundamental properties of solids and liquids, J. Am. Chem. Soc., 1916, 38, 2221-2295.

34- H.M.F. Freundlich, Uber die adsorption in losungen, Z. Phys. Chem., 1906, 57, 385-47029.

35- H. Zaghouane-Boudiaf, M. Boutahala, L. Arab. Removal of methyl orange from aqueous solution by uncalcined and calcined $\mathrm{MgNiAl}$ layered double hydroxides (LDHs), Chemical Engineering Journal, 2012, 187,142-149.

36- A. Aarfane, A. Salhi, M.El Krati, S. Tahiri, M. Monkade, E.K. Lhadi, M. Bensitel, Kinetic and thermodynamic study of the adsorption of Red195 and Methylene blue dyes on fly ash and bottom ash in an aqueous medium. J. Mater. Environ. Sci., 2014, 5 (6),1927-193.

37- N, Dalhat., S.A. Haladu, N. Jarrah, M. Zubair, M.H. Essa, S.A. Ali, Polyaspartate extraction of cadmium ions from contaminated soil: evaluation and optimization using central composite design, J. Hazard. Mater, 2018, 342, 58-68.
38- R, Shan, L, Yan, K, Yang, S, Yu, Y, Hao, H, Yu, $\mathrm{B}$, Du, Magnetic $\mathrm{Fe}_{3} \mathrm{O}_{4} / \mathrm{MgAl}-\mathrm{LDH}$ composite for effective removal of three red dyes from aqueous solution, Chem. Eng. J. 2014, 252, 38-46.

39-Y.M. Zheng, N. Li. W, De Zhang, Preparation of nanostructured microspheres of $\mathrm{ZnMg}-\mathrm{Al}$ layered double hydroxides with high adsorption property, Colloids Surf. A Physicochem. Eng. Asp, 2012, 415, 195-201

40-Y. Lu, B. Jiang, L. Fang, F. Ling, J. Gao, F. Wu, High-performance NiFe layered double hydroxide for methyl orange dye and $\mathrm{Cr}$ (VI) adsorption, Chemosphere, 2016, 152, 415-422.

41- A. Aishah, S. Jalil, S. Triwahyono, N. Hazirah Adam, M. Diana Rahim, A. Arif, N. Aziz, H. Hanis, N. Hairom, M. Aini, Razali., Mahani, A.Z. Abidin, M. Khairul, A. Mohamadiah, Adsorption of methyl orange from aqueous solution onto calcined Lapindo volcanic mud, J. Hazard. Mater, 2010, 181, 755-762.

42- Z. Ni, S. Xia, L.Wang, F.Xing, G.Pan, Treatment of methyl orange by calcined layered double hydroxides in aqueous solution: adsorption property and kinetic studies, J. Colloid Interface Sci., 2007, 316, 284-291.

43- Y. Iida, T. Kozuka, T. Tuziuti, K. Yasui, Sonochemically enhanced adsorption and degradation of methyl orange with activated aluminas, Ultrasonics, 2004, 42 635-639.

44- F. Krika, F. Benlahbib, Removal of methyl orange from aqueous solution via adsorption on cork as a natural and low-cost adsorbent: equilibrium, kinetic and thermodynamic study of the removal process, Desalin. Water Treat, 2015, 53, 3711-3723. 